\title{
Analysis of Relationships and Causality between Consumer Price Index (CPI), the Producer Price Index (PPI) and Purchasing Manager's Index (PMI) in South Africa
}

\author{
Daniel Francois Meyer, Thomas Habanabakize \\ North-West University, South Africa \\ daniel.meyer@nwu.ac.za, tomhaban12@gmail.com
}

\begin{abstract}
The variables the consumer price index (CPI), the producer price index (PPI) and the purchasing managers' index (PMI) and play major roles in economic forecasting. The overall objective of this study is to assess the inter-relationships between CPI, PPI and PMI as predicting variables. This study is quantitative in nature and employed an ARDL econometric model, error correction model (ECM) and Granger causality approaches to establish long and short-run relationships. The ARDL method was used due to the fact that the variables had a mix of stationarity at levels I (0) and the first difference I (1). Quarterly datasets were obtained from Statistics South Africa (Stats SA) and the Bureau of Economic Research (BER) for the period 2000 to 2017. Results from the estimations discovered that variables cointegrate in the long-run. Additionally, evidence of short-run relationships has been determined using ECM. Furthermore, causal relationships were also analysed with results indicating that CPI causes PMI and PPI causes PMI. The implication of the research is the confirmation of the importance of relationships between CPI, PPI and PMI, which is especially significant in the short-run and the three index indicators are important macro-economic indicators for changes in overall economic activity on a macro level.
\end{abstract}

Keywords: $A R D L, C P I, P M I, P P I$, South Africa

\section{Introduction}

An economy in the world is analyzed by means of critical macroeconomic variables such as inflation, GDP growth, unemployment rates, exchange rates (Auerbach \& Gorodnichenko, 2012). In this study, a different approach was followed where three macroeconomic indexes were selected that have not been included in econometric models on a regular basis. Economists regularly speculate about the relationships between inflation or consumer price index (CPI), producer price index (PPI) and the purchasing managers' index (PMI). All three variables are seen as predictors of general economic activities in the business cycle of an economy, but each variable has a different focus in the economy. In time periods of high levels of economic activity and economic expansion, such activities could result in increased employment, with rising income and consumer expenditure leading to increased demand for goods and services as well as commodities. Such an increase in economic growth usually results in skills shortages and other macroeconomic problems such as supply backlogs. Such a situation where demand outperforms supply, usually leads to price instability and inflation due to higher production costs and demand (IHS Markit, 2017). The research question that is under investigation in this paper is focused on the inter-relationships between the predicting index variables of CPI, PPI and PMI. The overall objective of the study is to determine the relationships between the three variables. This study is unique and important in that limited studies have analyzed the three variables together and these indexes and their relationships are different in developed and developing countries.

This study analyzed the situation in a developing country, namely South Africa, which is seen in many cases as a proxy for emerging economies. The results of this study could present important findings for future policy formulation. CPI could be defined as the general, continuous and sustained escalation in price levels of services and goods in an economy and the average price level is measured by means of the CPI (Fourie \& Burger, 2017). According to Mohr (2001) the CPI is the most used economic indicator in South Africa and CPI is used to calculate inflation rates on a monthly basis. According to Dornbusch et al., (2014), PPI is also described as a measure of the cost of a basket of goods, similar to CPI, but, PPI has a more limited and different range of goods included in the measurement. PPI includes only raw materials and semi-finished goods and measures good in the early stage of the distribution and supply chain system. Mohr (2001) states that PPI is also estimated on a monthly basis and measures the price level of the "first significant commercial transaction". Prices of manufactured goods are for example measured where they leave the factory. PPI is therefore different to CPI as it measures the cost of production whereas CPI measures the cost of living 
(Mohr, 2001). According to Mohr, (2001) the link between CPI and PPI is that changes in PPI indicate possible movements or changes in CPI.

PMI is defined as a composite index that measures growth and activity in manufacturing and also indirectly, the total economy of a country (Chien \& Morris, 2016). In addition, Aprigliano (2011) states that PMI provides timely information on the spread of improvement or deterioration of business conditions. PMI is compiled through surveys of purchasing and supply conditions in a country or region (Khundrakpam \& George, 2013). Purchasing managers are surveyed on their short-run purchases and production conditions and decisions and could therefore be classified as a leading economic indicator (Khundrakpam \& George, 2013; Pelaez, 2003; Tsuchiya, 2012). PMI data is available in the beginning of every month, before most other macroeconomic datasets. According to Khundrakpam and George (2013), PMI is used by many central banks to analyse overall economic activities relating to strength and direction. The rest of the study layout firstly includes a literature review which consists of an analysis of concepts, and an empirical review of quantitative results of previous studies; secondly the research methodology is explained with the associated empirical results and findings. Lastly, recommendations are made with some concluding remarks.

\section{Literature Review}

In this section an empirical overview of the relationships amongst the variables included in the study is provided as well as an analysis of the predictability value of the variables regarding the economy. Liping, Gang and Jiani, (2008) analysed the relationship between CPI and PPI in China utilizing a Granger-causality examination for the period from 2001 to 2008 . They found that movement in CPI causes changes in PPI. PPI reacted to changes in CPI with a 1-3-month time lag. This indicates that demand-side factors could play a dominating role if compared to the supply-side factors in the Chinese economy. Akcay, (2011) also analysed the relationship between CPI and PPI in selected European countries from 1995 to 2007, also using a Granger causality test to determine causality. The results are not standard for all five countries. Some countries indicated uni-directional causality from PPI to CPI while other countries presented a bi-directional causality. Caporale, Katsimi and Pittis, (2002) investigated the relationship amongst CPI and PPI in the G7 countries, employing causality testing method. A summary of the results confirmed uni-directional causality from PPI to CPI. Barnes (2017), states that PMI is a significant indicator of general economic activities as most recessions or boom periods start in the manufacturing sector.

The PMI is a score between 0 and 100. For example, a PMI of 50 indicates that an equal number of managers indicated that conditions are better compared to getting worse. A PMI of 50 and above therefore indicates a possible expansion of specifically the manufacturing sector (Koenig, 2002). In South Africa (SA), the PMI is compiled by BER on a monthly frequency based on the principles as used by the Institute of Supply Management (ISM) in the US. PMI's strengths of a leading indicator are the freshness of data, power to explain and understand other indicators better, shows trends in changes and analyse supply in the commodity sectors (Barnes, 2017). PMI could be utilised as an effective forecaster of changes in GDP, inflation and economic sectors, especially manufacturing activity (Lindsey \& Pavur, 2005; Tsuchiya, 2012). It should however be noted that the strength of PMI as a leading indicator, has in recent years lost some of its power due to the diminishing role of manufacturing in the global economy (Barnes, 2017). Banerjee and Marcellino (2006) also tested the relationship between PMI, inflation and GDP growth in the US and found a significant relationship between indicators.

For the period 2005 to 2012, using an ARDL econometric method, it was found that PMI was a significant predictor of inflation and economic activities as well as the manufacturing growth in India (Khundrakpam \& George, 2013). Rossiter (2010) analysed the relationships between various macroeconomic variables where the author utilized mixed-frequency forecasting equations for global quarterly economic output, imports, and inflation using PMI. The results of the study indicated that PMI is valuable in predicting changes in the economy. In period of shocks such as the financial crises in 2008, the PMI did not fully predict the changes in the economy. This study emphasises the usefulness nature of indicators such as PMI for short-term forecasting. Paterson (2014) analysed the relationship between inflation and PMI. The results of the study within a boom period in the UK, was that inflation was increasing in tandem with PMI on a monthly basis indicating that PMI was causing changes in CPI on the short term. In conclusion literature on the relationships 
between the selected indexes limited. Findings from the literature indicate that PMI is a leading indicator that can be successfully utilized to predict changes in other indexes and macroeconomic indicators regarding the general economic conditions, but more specifically the manufacturing sector. Other researchers have also confirmed that PPI could in most cases cause changes in CPI.

\section{Research Methodology}

The study is based on a quantitative research methodology. The study used time series data for the period 2000 to 2017, with quarterly data. The data was retrieved from Statistics South Africa (Stats SA) and from the Bureau of Economic Research (BER) databases. The variables included in the analysis are: consumer price index (CPI); purchasing managers' index (PMI) and the producer price index (PPI). These variables were chosen given their significant forecasting value in the South African economy and the relationship that might exist amongst the variables. The time evolution or changes in time series trends for each variable are provided in Figure 1. CPI and PPI indexes indicating price changes over time with a specific base year, and have experienced upward trending movements. PMI on the other hand indicates the outlook of purchasing managers on the economy and has shown more volatile trends in both directions as the economy goes through boom and bust periods. For uniformity and stability purposes, variables were differenced, and nonstationary series are used to determine the long-run relationship. Thereafter, each deviation or shock from the equilibrium is expected to adjust in following periods (Engle \& Granger, 1987). The general consensus from the literature is therefore that the order of causality is as follows: PMI causes PPI to change which causes CPI to change.

\section{Figure 1: Graphical Representation of CPI, PMI and PPI}

CPI
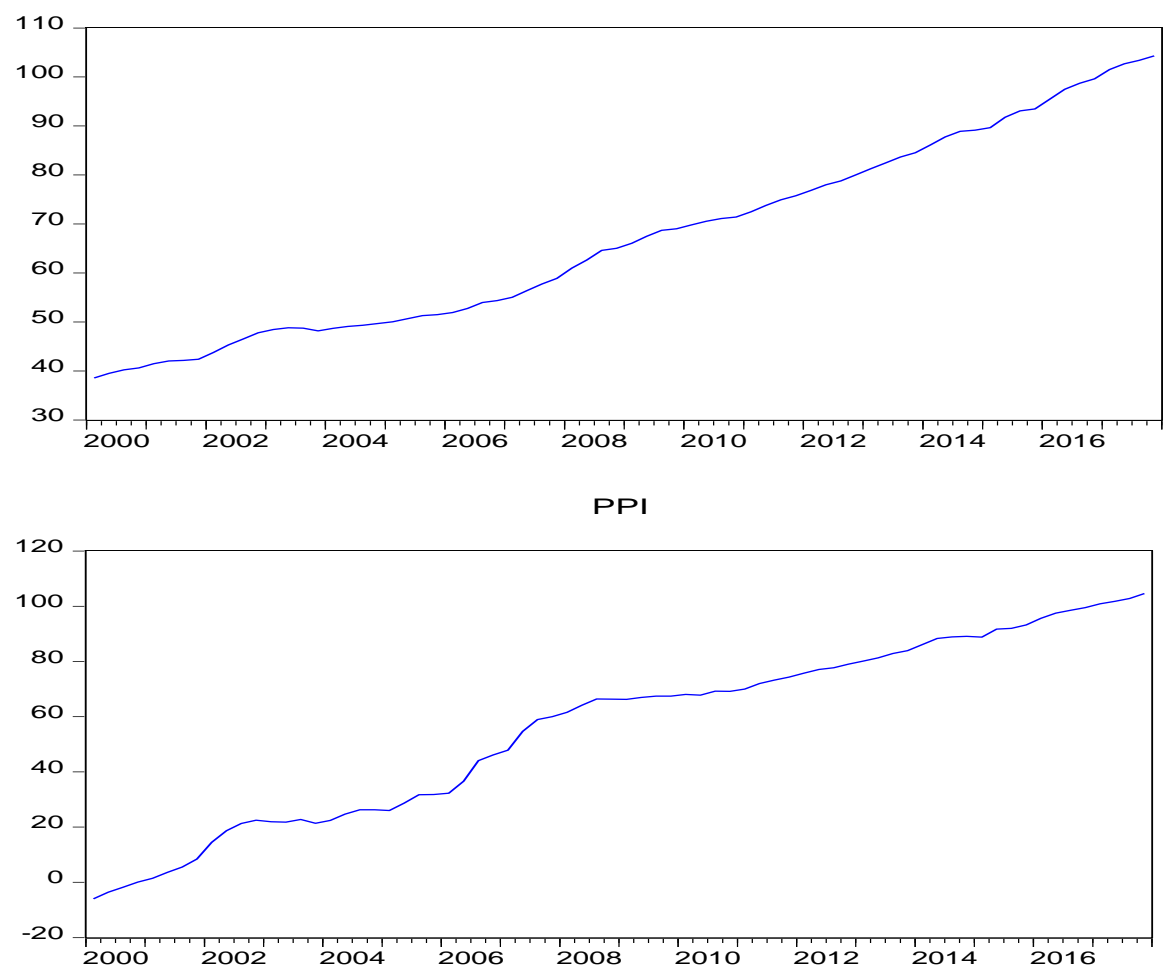


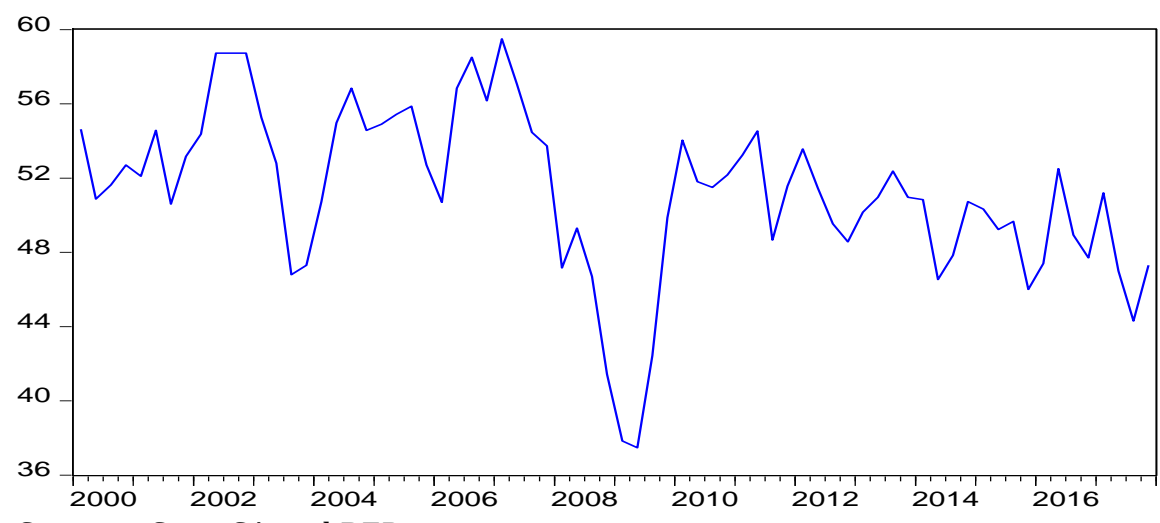

Sources: Stats SA and BER.

Numerous econometric models and approaches exist to determine or test long-run effects amongst economic and financial time series variables. During the last few decades, the impact of works of scholars such as Engle and Granger (1987), Johansen (1988), and Pesaran and Smith (1998) are recognised in the econometric field. Nonetheless, to achieve the objective of this study, the Autoregressive Distributed Lag (ARDL) model, introduced by Pesaran and Smith (1998) and revised by Pesaran et al. (2001), is chosen. The choice of this model was made based on its numerous advantages of the model. Firstly, the ARDL model has the ability to simultaneously estimate the long and short-run relationships. Secondly, it can be applied to variables that have a mixture of stationary, both I (0) and I (1). Thirdly, the ARDL model allows the utilization of different numbers of optimum lags. Furthermore, it is an appropriate model to determine the cointegration or long-run relationship while using a small sample size. The only drawback of this model is its inability to provide accurate results when applied to variables that are I (2) (Omar et al., 2015).

Applying a linear relationship and following the econometric empirical literature, the inter-relationship between CPI, PMI and PPI can be expressed as:

$C P I_{t}=\mathrm{F}\left(P M I_{t}, P P I_{t}, u_{t}\right)$

$P M I_{t}=\mathrm{F}\left(C P I_{t}, P P I_{t}, u_{t}\right)$

$P P I_{t}=\mathrm{F}\left(C P I_{t}, P M I_{t}, u_{t}\right)$

Where $u$ represents an error term and $t$ denotes a time index. To analyse relationships on the long-run, amongst the variables, a Bounds test, built on F-statistics or Wald test suggested by Pesaran et al., (2001) was used. In these tests, the null hypothesis proposes the absence of cointegration, while the alternative hypothesis indicates the presence of cointegration between variables. The CPI equation with the unrestricted error correction model (UECM) is considered as:

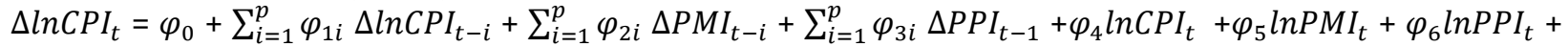
$u_{t}$

Where $\triangle \ln C P I, \triangle \ln P M I$ and $\triangle \ln C P I$ denote first differences of analysed variables. This equation is repeated three times for each of the three variables (because each variable is firstly treated and dependent, then independent). To test the null hypothesis of no cointegration, the UECM is considered. The set of the null hypothesis and the alternative hypothesis are represented as follow:

$H_{0}=\varphi_{4}=\varphi_{5}=\varphi_{6}=0$

$H_{1} \neq \varphi_{4} \neq \varphi_{5} \neq \varphi_{6} \neq 0$

Provides tables comprising of two sets: the lower bound critical values indicating I $(0)$ and the upper bound critical values indicating series that are I(1). Such a conclusion can only be made if the F-statistics falls outside bounds. In other words, if the F-statistics is greater than the upper bound critical values, the null hypothesis suggesting no cointegration is rejected. Alternatively, if the F-statistics is smaller than the lower bound, the null hypothesis is not rejected meaning the lack of a long-run relationship. However, if the F-statistics fall 
between the two bounds, unless further information, no conclusion can be made. The equilibrium relation of long-run ARDL (q1, q2, q3) can be express as follow:

$$
\operatorname{lnCPI_{t}}=\alpha_{0}+\sum_{i=1}^{q 1} \delta_{1 i} \operatorname{lnCPI_{t-i}}+\sum_{i=1}^{q 2} \delta_{2 i} P M I_{t-i}+\sum_{i=1}^{q 3} \delta_{3 i} P P I_{t-1}+e_{t}
$$

Where $e_{t}$ denotes the gap between $\ln C P I_{t}$ and its equilibrium level, which is to be adjusted in the next quarter. This equation is repeated three times (because each variable is firstly treated and dependent, then independent). Subsequently, the outcome of the model expressing the speed of adjustment is expressed as: $\Delta l n C P I_{t}=\vartheta_{0}+\sum_{i=1}^{q} \vartheta_{1 i} \Delta l n C P I_{t-i}+\sum_{i=0}^{q} \vartheta_{2} \Delta P M I_{t-i}+\sum_{i=0}^{q} \vartheta_{3} \Delta P P I_{t-1}+\vartheta_{4} \varepsilon_{t-1}+u_{t}$ (6). In Equation (6), $\varepsilon_{t-1}$ denotes the error correction term. Its coefficient $\vartheta_{4}$ is expected to negative and significant. It expresses the speed of adjustment for the consumer price index (explained variables) towards the long run equilibrium. Equation (6) is repeated three times (because each variable is firstly treated and dependent, then independent). To ensure the accuracy of the ARDL model used in the study, stability and diagnostic tests are performed. Diagnostic test includes serial correlation, normality and heteroscedasticity.

\section{Analysis and Empirical Results}

Approach Dolado, Sosvila-Rivero Jenkinson (1990) were used for unit root testing and the outcome suggested the absence of deterministic trends within the series under investigation. The Augmented Dicky-Fuller (ADF) test was performed for unit root testing. Table 1 is a summary of the outcomes of the tests. As indicated, the variables under investigation comprise of I (0) and I (1) variables, supporting the choice of the use of an ARDL model for cointegration analysis.

Table 1: ADF Test Results

\begin{tabular}{llllll}
\hline Variables & \multicolumn{2}{l}{ Variables in Levels } & \multicolumn{2}{l}{ Variables in First Difference } & Integration \\
order (result) \\
CPI & Constant & constant \& trend & constant & constant \& trend & \\
PMI & 0.9999 & 0.6687 & 0.0596 & $0.0001^{*}$ & I (1) \\
PPI & $0.0447^{* *}$ & $0.0157^{* *}$ & $0.0000^{*}$ & $0.0000^{*}$ & I (0) \\
\cline { 1 - 4 } & 0.6777 & 0.3069 & $0.0100^{*}$ & $0.0255^{* *}$ & I (1) \\
\hline
\end{tabular}

Note. ${ }^{*}, * *$ indicate significance of variable at $1 \%, 5 \%$ respectively.

The procedure of ARDL analysis begins with the lag order selection (p) as represented in the equations (1), (2) and (3). Different criteria are available for lag length selection. In this study, the Schwartz Information Criterion (SIC) was used and the best models selected were ARDL $(2,0,1)$ for the CPI model, ARDL $(1,0,1)$ for the PMI model and ARDL $(3,0,2)$ for the PPI model suggesting that $p=2$ is the right lag length for CPI, $p=$ 1 for the PMI, and $p=3$ for PPI. The optimal numbers of lags were used in determining the existence of a longrun relationship amongst the variables using the Wald test. Using the F-statistics results, the conclusion was that a long-run relationship exists amongst the analysed variables. The F-statistics value is 6.84 for the first model; 4.59 for the second model and 3.47 for the third model. The F-test for model 1 and model 2 (as presented in the equation 1 and 2) are greater than the upper bound (4.38) critical value from the Narayan (2004:28) tables, with a significant alpha of 0.05 or 0.95 interval level of confidence. Henceforth, the null hypothesis of no cointegration is rejected in favour of the alternative. Thus, under the ARDL model with the optimum number of lags (q1, q2, and q3), variables are cointegrated.

As explained in the previous paragraph and displayed in Table 2, a long-run relationship (cointegration) exists. Therefore, it is pertinent to analyse that relationship using the long-run coefficients as indicated in equations (7), (8) and (9):

$\mathrm{CPI}=84.88-0.989 * \mathrm{PMI}+1.301 * \mathrm{PPI}$.

$\mathrm{PMI}=89.68+0.085^{*} \mathrm{CPI}-0.103 * \mathrm{PPI}$

$\mathrm{PPI}=196.79+0.667^{*} \mathrm{CPI}+0.5023^{*} \mathrm{PMI}$

The highlights from the three equations are that a 1 percent increase in PPI could cause CPI to increase by 1.3 percent; both CPI and PPI have limited impact on PMI; and both CPI and PMI have positive and above 0.5 
percent impacts on PPI. These results are similar to findings by Caporale et al., (2002) and Barnes (2017). The result in Table 2 indicates the accuracy and goodness fit of the used model. The LM test confirms that no serial correlation exists and the ARCH test revealed that variables are homoscedastic. Additionally, the variables are normally distributed according to the Jarque-Bera test Furthermore, the CUSUM stability test result, reported in Figure 2, proved models to be stable.

Table 2: The ARDL Diagnostic Tests

\begin{tabular}{|c|c|c|c|}
\hline Variables & CPI & PMI & PPI \\
\hline F-stat & $6.8480^{*}$ & $4.5983^{* *}$ & $3.4734^{*}$ \\
\hline $\begin{array}{l}\text { LM test (serial } \\
\text { correlation) }\end{array}$ & 0.0634 & 0.2791 & 0.3995 \\
\hline ARCH (homoscedasticity) & 0.3821 & 0.7215 & 0.7841 \\
\hline $\begin{array}{l}\text { Jarque-Bera (normality } \\
\text { test) }\end{array}$ & 0.8075 & 0.5120 & 0.3170 \\
\hline
\end{tabular}

Note. ${ }^{*}, *$ indicate the significance of variable at $1 \%$ and $5 \%$, significance respectively.

Table 3: Short Run and Error Correction Models

\begin{tabular}{|c|c|c|c|}
\hline Variables & CPI & PMI & PPI \\
\hline $\mathrm{D}(\mathrm{CPI})$ & & & 1.6499* \\
\hline $\mathrm{D}(\mathrm{CPI}(-1))$ & $0.2580^{*}$ & $0.5984^{* *}$ & $-0.7044^{*}$ \\
\hline $\mathrm{D}(\mathrm{PMI})$ & -0.0019 & ---------- & $0.08440^{*}$ \\
\hline $\mathrm{D}(\mathrm{PPI})$ & $0.1820^{*}$ & -0.1811 & ----------- \\
\hline $\mathrm{D}(\mathrm{PPI}(-1))$ & --------- & --------- & $0.3935^{*}$ \\
\hline D(PPI(-2)) & --------- & ---------- & $-0.2210^{* *}$ \\
\hline ECT & $-0.0100 *$ & $-0.3362^{*}$ & $-0.0184^{*}$ \\
\hline
\end{tabular}

Note: ${ }^{*}{ }^{* *}$ indicate significance of variable at $1 \%, 5 \%$ significance levels respectively.

Figure 2: Stability Tests Results

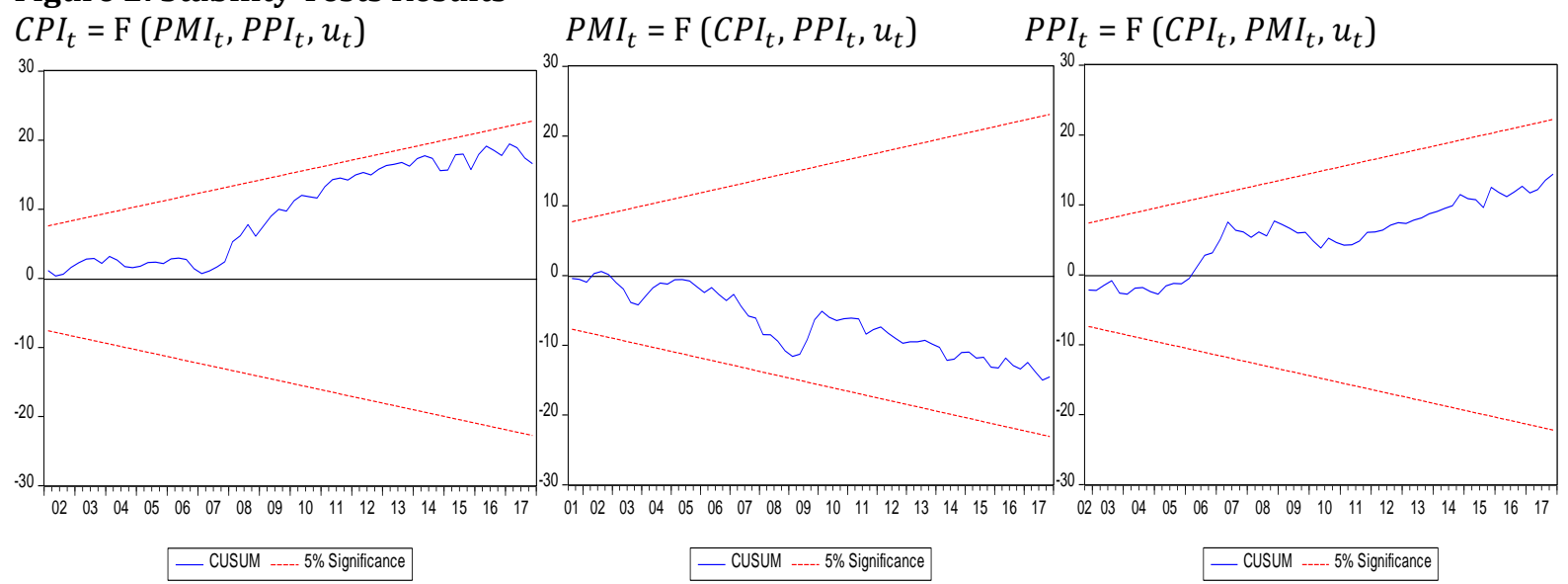

All variables in this study also interact in the short-run. This interaction is proven by the significant outcomes as indicated. The short-run level of CPI depends on PPI behaviour, but also on previous or lagged levels of CPI which is similar to findings by Liping et al., (2008). In contrast, the CPI level impact on both PMI and PPI. Nonetheless, PPI does not significantly affect PMI. Both CPI and PMI impact on PPI and PPI also responds to its own shocks. In addition, the results indicate that any short-run disequilibrium in the model is adjusted in the next quarters back to equilibrium. A Granger causality test was conducted to determine the causal relationships amongst the variables under consideration on the short-run and the test outcome is reported in Table 4. Based on this result, a uni-directional causal relationship exists between CPI and PMI. In other words, CPI is a predictor of PMI. Similar findings were also found by Paterson (2014). Uni-directional causality 
occurs between PPI and PMI; that is to say, in short- run, changes in PPI can predict the PMI behaviours, with similar findings by Barnes (2017).

Table 4: Granger Causality Results

\begin{tabular}{lll}
\hline Null Hypothesis: & F-Statistic & Prob. \\
\hline PMI does not cause CPI & 0.06996 & 0.9325 \\
CPI does not cause PMI & 2.88814 & $0.0429^{*}$ \\
PPI does not cause CPI & 1.99922 & 0.1437 \\
CPI does not cause PPI & 0.98531 & 0.3788 \\
PPI does not cause PMI & 3.14092 & $0.0499^{*}$ \\
PMI does not cause PPI & 1.24331 & 0.2952 \\
\hline
\end{tabular}

Note: *indicate significance of variable at $5 \%$ significance level.

\section{Conclusion}

This study analysed the inter-relationships and causality between CPI, PMI and PPI in the South African economy between 2000Q1 and 2017Q4. Firstly, a long-run interrelationship was examined and cointegration was found in the series. Nonetheless, the short-run behaviour of each variable can impact on the other variables in the model. In addition, causality tests were also performed and the outcomes revealed two unidirectional causal relationships: firstly, between CPI and PMI, and secondly between PPI and PMI. Based on this result, it is pertinent to indicate that although the variables cointegrate in the long-run their impact is more effective in the short-run. Thus the relationships between CPI, PMI, and PPI are more of a concern in formulating short-term than long-term economic policies in the South African environment. Interesting to note from this study is that the results are not exactly what was expected and what was found during the literature review process. Findings from the literature indicate that PMI is a leading indicator that can be successfully utilized to predict changes in other indexes and macroeconomic indicators regarding the general economic conditions, but more specifically the manufacturing sector. Other researchers have also confirmed that PPI could in most cases cause changes in CPI. The general consensus from the literature is therefore that the order of causality is as follows: PMI causes PPI to change which causes CPI to change. In this study on the South African situation, it was found that the causality between the variables different to what was expected. It was found that CPI causes PMI and PPI causes PMI and not vice versa.

The implication of the research is the confirmation of the importance of relationships between CPI, PPI and PMI, which is especially significant in the short-run and the three index indicators are important macroeconomic indicators for changes in overall economic activity on a macro level. These results indicate that more research is needed on the relationship between these variables and also other variables could be introduced. Although long-run cointegration was found amongst variables, the short-run results are interesting as it were different to traditional perceptions of the causality. The study has interesting and significant impacts for monetary policy formulation for developing countries. Each country is unique and a different set relationship between economic variables. Finally, it can be concluded that economic indexes are still important predictors for economic conditions but causality between variables differ from region to region.

\section{References}

Akcay, S. (2011). The causal relationship between producer price index and consumer price index: Empirical evidence from selected European countries. International Journal of Economics and Finance, 3(6), 227-235.

Aprigliano, V. (2011). The relationship between the PMI and the Italian index of industrial production and the impact of the latest economic crisis.

Auerbach, A. J. \& Gorodnichenko, Y. (2012). Fiscal multipliers in recession and expansion. In Fiscal policy after the financial crisis (pp. 63-98). University of Chicago Press. 
Banerjee, A., Dolado, J. \& Mestre, R. (1998). Error-correction mechanism tests for cointegration in a single equation framework. Journal of Time Series Analysis, 19(3), 267-283.

Barnes, R. (2017). Economic Indicators: Purchasing Managers Index (PMI).

BER. (2015). PMI: A monthly index of business conditions in the manufacturing sector.

Caporale, G. M., Katsimi, M. \& Pittis, N. (2002). Causality links between consumer and producer prices: some empirical evidence. Southern Economic Journal, 703-711.

Chien, Y. \& Morris, P. (2016). PMI and GDP: Do They Correlate for the United States? For China? Economic Synopses, Issue 6, 1-2.

Dolado, J., Jenkinson, T. \& Sosvilla-Rivero, S. (1990). Cointegration and unit roots. Journal of Economic Surveys, $4(3), 249-273$.

Dornbusch, R., Fischer, S. \& Startz, R. (2014). Macroeconomics. New York: McGraw-Hill Publishers.

Engle, R. F. \& Granger, C. W. (1987). Cointegration and Error Correction: Representation, Estimation and Testing. Econometrica, 55 (2), 251-276.

Fourie, F. \& Burger, P. (2017). How to think and reason in Macroeconomics. Cape Town: Juta and Company.

Hansen, B. E. \& Phillips, P. C. (1990). Estimation and inference in models of cointegration: A simulation study. Advances in Econometrics, 8(1989), 225-248.

IHS Markit. (2017). Interpreting PMI data.

Johansen, S. (1988). Statistical Analysis of Cointegration Vectors. Journal of Economic Dynamics and Control, 12(2-3), 231-254.

Khundrakpam, J. K. \& George, A. T. (2013). An Empirical Analysis of the Relationship between WPI and PMIManufacturing Price Indices in India.

Koenig, E. F. (2002). Using the purchasing managers' index to assess the economy's strength and the likely direction of monetary policy. Federal Reserve Bank of Dallas, Economic and Financial Policy Review, 1(6), 1-14.

Lindsey, M. D. \& Pavur, R. (2005). As the PMI Turns: A Tool for Supply Chain Managers, the Journal of Supply Chain Management, 41(3), 30-39.

Liping, H., Gang, F. \& Jiani, H. (2008). CPI vs. PPI: Which Drives Which? Economic Research Journal, 11, 16-26.

Mohr, P. (2001). Economic Indicators. Pretoria: University Press.

Omar, W. A. W., Hussin, F. \& GH, A. A. (2015). The Empirical Effects of Islam on Economic Development in Malaysia. Research in World Economy, 6(1), 99-111.

Paterson, T. (2014). UK manufacturing PMI.

Pelaez, R. F. (2003). A new index outperforms the purchasing managers' index. Quarterly Journal of Business and Economics, 41-55.

Pesaran, M. H. \& Shin, Y. (1998). An autoregressive distributed lag modelling approach to cointegration analysis. Econometric Society Monographs, 31, 371-413.

Pesaran, M. H., Shin, Y. \& Smith, R. J. (2001). Bounds Testing Approaches to the Analysis of Level Relationships. Journal of Applied Econometrics, 16(3), 289-326.

Rossiter, J. (2010). Now casting the Global Economy. Bank of Canada Discussion Paper No. 2010-12. Bank of Canada.

Tsuchiya, Y. (2012). Is the Purchasing Managers' Index useful for assessing the economy's strength? A directional analysis. Economics Bulletin, 32(2), 1302-1311. 